\title{
CONSEQÜÊNCIAS FISIOLÓGICAS DA DESSECAÇÃO EM SEMENTES DE AÇAÍ (Euterpe oleracea Mart.) ${ }^{1}$
}

\author{
WALNICE MARIAOLIVEIRADO NASCIMENTO², ANADIONISIADALUZCOELHO NOVEMBRE ${ }^{3}$, SILVIO MOURE CICERO $^{3}$
}

\begin{abstract}
RESUMO - O presente trabalho foi realizado com o objetivo de verificar os efeitos imediatos da desidratação sobre a qualidade fisiológica de sementes de açaí. Anteriormente à secagem das sementes da cultivar BRS Pará foi determinado o teor de água das mesmas e selecionado o lote daquelas que apresentavam o maior teor de água, que foi de $43,4 \%$. As sementes foram submetidas à secagem, em equipamento com circulação forçada de $\operatorname{ar}\left(30 \pm 2^{\circ} \mathrm{C}\right)$, até atingirem o teor de água de $37,4 \%, 30,3 \%$ 26,1\%, 21,0\%, 15,\% e 11,9\%, constituindo os demais tratamentos. O efeito da secagem sobre a qualidade das sementes foi avaliado por meio das determinações de germinação, tempo médio de germinação, velocidade de emergência, comprimento e massa da matéria seca de plântulas. A secagem até 37,4\% de água não produz efeitos fisiológicos prejudiciais imediatos sobre as sementes de açaí, contudo, abaixo de 30,3\% há redução progressiva da germinação e do vigor das sementes e ao atingirem 15,1\% de teor de água, o desempenho fisiológico é anulado.
\end{abstract}

Termos para indexação: palmeira, vigor, deterioração.

\section{PHYSIOLOGICAL CONSEQUENCES OF DESICCATION IN Euterpe oleracea Mart. SEEDS}

\begin{abstract}
This study was carried out to investigate the immediate effects of dehydration on the physiology in Euterpe oleracea Mart. seeds. Before drying the BRS Pará variety seeds, the seed moisture content was determined and the lot with the highest moisture content $43.4 \%$ was selected. The seeds were submitted to drying, in equipment with forced air circulation $\left(30 \pm 2^{\circ} \mathrm{C}\right)$, until the moisture content reached 37.4\%, 30.3\%, 26.1\%, 21.0\%, 15.1\% and 11.9\% and comprised the other treatments. The effect of dehydration on seed quality was evaluated by determining the germination percentage, mean germination period, emergence speed, seedling length and seedling dry matter weight. The dehydration up to $37.4 \%$ of moisture dids not produce immediate effects on the physiologic behavior of the Euterpe oleracea seeds, but over 30.3\% there was progressive reduction in seed germination and vigor and when $15.1 \%$ of moisture content was reached, the physiologic performance was annulled.
\end{abstract}

Index terms: palm tree, vigour, deterioration.

\section{INTRODUÇÃO}

A palmeira Euterpe oleracea (Mart.), conhecida como açaizeiro, tem se destacado economicamente pelo potencial mercadológico de seus produtos, representados principalmente, pelo palmito e pelo suco extraído do fruto. Dessa maneira, a partir da disponibilidade de material propagativo, a exploração extrativista tem sido parcialmente substituída por cultivos em campos de produção.

\footnotetext{
1. Submetido em 17/12/2005. Aceito para publicação em 09/03/2007 Parte da Tese de Doutorado do primeiro autor apresentado a USP/ESALQ.

2. Eng. Agr ${ }^{\circ}$, Dr. Pesquisador da Embrapa Amazônia Oriental, caixa postal
}

A semente do açaizeiro, que corresponde ao fruto desprovido de epicarpo e parte do mesocarpo, contém um eixo embrionário diminuto e abundante tecido endospermático de formato esférico e que representa $73 \%$ da massa do fruto completo (Villachica et al., 1996; Carvalho et al., 1998).

Em relação ao armazenamento, as sementes podem ser classificadas em recalcitrantes ou ortodoxas. Em sementes denominadas recalcitrantes, a desidratação causa alterações que favorecem a deterioração. Sementes das espécies Euterpe

48, CEP 66095-100, Belém, PA, walnice@cpatu.embrapa.br

3. Eng. Agr ${ }^{\circ}$., Dr. Professor do Departamento de Produção Vegetal da USP/ ESALQ - caixa postal, 9, CEP: 13418-900, Piracicaba, SP, smcicero@esalq.usp.br, adlcnove@esalq.usp.br 
oleracea Mart. (açaizeiro) e Euterpe edulis Mart. (palmiteiro) são consideradas recalcitrantes (Carvalho et al., 1998; Araújo et al., 1994; Andrade e Pereira, 1997) e a secagem pode causar alterações que favorecem a sua deterioração (Farrant et al., 1988). A secagem de sementes de açaizeiro até teores de água de aproximadamente $14 \%$ foi suficiente para reduzir a capacidade germinativa das mesmas (Oliveira et al., 2000). Da mesma forma, Martins et al. (1999b) verificaram o caráter recalcitrante em sementes de Euterpe espiritosantensis (palmito-vermelho) e comprovaram que a desidratação crescente intensificou o processo de deterioração. Os valores de germinação foram reduzidos e a mortalidade das sementes foi observada com a redução do teor de água para 16\%.

Para as espécies tropicais nativas, o conhecimento do menor grau de umidade suportável pelas sementes, sem que haja o comprometimento da qualidade fisiológica é imprescindível para definir a melhor tecnologia de armazenamento de sementes. Através dessa informação, a conservação das sementes pode ser viabilizada, mediante a secagem parcial, sem que haja o comprometimento na porcentagem de germinação. $\mathrm{O}$ armazenamento de sementes recalcitrantes com teores de água relativamente altos, mas insuficientes para permitir a germinação, tem permitido a obtenção de resultados favoráveis. Diante disso, esse trabalho teve como objetivo verificar os efeitos da redução do grau de umidade sobre o desempenho fisiológico das sementes de Euterpe oleracea Mart., visando subsidiar futuros trabalhos sobre a conservação de sementes dessa espécie.

\section{MATERIAL E MÉTODOS}

A pesquisa foi realizada no Laboratório de Análise de Sementes do Departamento de Produção Vegetal pertencente à Escola Superior de Agricultura “Luiz de Queiroz”/USP (Piracicaba/SP).

Foram utilizadas sementes de açaí (Euterpe oleracea Mart.) da cultivar BRS Pará. Imediatamente após a colheita, os frutos maduros foram submetidos à extração do epicarpo e do mesocarpo em despolpadora mecânica, à lavagem para eliminação dos resíduos e à seleção manual, objetivando o descarte daqueles mal formados ou parcialmente danificados.

Anteriormente à secagem, foi determinado o teor de água inicial das sementes (Brasil, 1992). Amostras foram homogeneizadas para compor o tratamento que continha sementes com o maior teor de água (43,4\%). As sementes remanescentes foram submetidas à desidratação em equipamento com circulação forçada de $\operatorname{ar}\left(30 \pm 2^{\circ} \mathrm{C}\right)$, até teores de água de 37,4\%, 30,3\%, 26,1\%, 21,0\%, 15,1\% e 11,9\%, constituindo assim, os demais tratamentos. Cada tratamento foi definido após a determinação do teor de água das sementes. $\mathrm{O}$ teor de água foi determinado pelo método da estufa a $105^{\circ} \mathrm{C} \pm 3^{\circ} \mathrm{C}$ por 24 horas (Brasil, 1992), utilizando quatro repetições com 10 sementes cada. Os resultados, expressos em porcentagem, foram calculados com base na massa úmida (Bu).

Durante a secagem as sementes foram distribuídas em camada única, sobre bandejas de alumínio e os tratamentos foram obtidos por meio do acompanhamento da perda de água das sementes durante a secagem. Para monitorar o processo, amostras de sementes com massa inicial conhecida foram acondicionadas em sacos de filó e distribuídas nas prateleiras do secador para pesagem em intervalos regulares. A massa final das amostras, correspondente aos teores de água desejados, foi previamente determinada por meio da equação descrita por Cromarty et al. (1985):

$\mathrm{Mf}=\frac{\mathrm{Mi}(100-U i)}{100-U f}$, onde:

Mf = massa da amostra (g) após a secagem;

$\mathrm{Mi}=$ massa da amostra (g) antes da secagem;

$\mathrm{Ui}$ = grau de umidade (\%) antes da secagem;

Uf = grau de umidade (\%) desejado após a secagem.

A análise dos dados relativos ao processo de dessecação das sementes foi realizada por meio de regressão e ajuste de curva, utilizando-se o modelo sigmoidal de Boltzman (Statsoft, 1998).

As sementes foram submetidas às avaliações discriminadas a seguir.

Germinação - Realizada entre areia, umedecida com 70\% de sua capacidade de retenção de água (Brasil, 1992). Cinqüenta sementes por repetição foram semeadas em bandejas de plástico a $1 \mathrm{~cm}$ de profundidade em ambiente protegido e desprovido de controles de temperatura e de umidade relativa. Os resultados, obtidos aos 90 dias após a semeadura, foram expressos em porcentagem de plântulas normais.

Tempo médio de germinação - Foi realizado em conjunto com o teste de germinação, determinado a cada três dias, anotando-se o número de plântulas emersas, em cada parcela. Para estimar o tempo médio de germinação (TM), foi utilizada a equação de Edmond e Drapala, segundo Silva e Nakagawa (1995), em que se obteve o índice que representa 
a média ponderada do tempo necessário para a germinação:

$$
\mathrm{Tm}=\frac{G 1 T 1+G 2 T 2+\ldots+G n T n}{G 1+G 2+\ldots+G n}, \text { em que: }
$$

$\mathrm{Tm}$ = tempo médio, para germinação da amostra;

$\mathrm{G}_{1}, \mathrm{G}_{2}$ e $\mathrm{G}_{\mathrm{n}}=$ número de sementes germinadas nos tempos $T_{1}, T_{2}$ e $T_{n}$, respectivamente.

Velocidade de emergência de plântulas Concomitantemente ao teste de germinação, foram realizadas contagens a cada três dias, durante 90 dias, do número de plântulas emersas, ou seja, com a parte área acima da superfície do substrato. O cálculo do índice de velocidade de emergência (IVE) foi realizado conforme a equação proposta por Maguire (1962):

$\operatorname{IVE}=\left(\mathrm{E}_{1} / \mathrm{N}_{1}\right)+\left(\mathrm{E}_{2} / \mathrm{N}_{2}\right)+\ldots+\left(\mathrm{E}_{\mathrm{n}} / \mathrm{N}_{\mathrm{n}}\right)$, onde:

IVE = Índice de velocidade de emergência de plântula.

$\mathrm{E}_{1}, \mathrm{E}_{2}, \ldots, \mathrm{E}_{\mathrm{n}}=$ números de plântulas emersas na primeira, segunda... e última contagens.

$\mathrm{N}_{1}, \mathrm{~N}_{2}, \ldots, \mathrm{N}_{\mathrm{n}}=$ número de dias da semeadura à primeira, à segunda... e à última contagens.

Comprimento de plântulas - Foram avaliados os comprimentos, em centímetros, da parte aérea, que correspondeu à distância do nó cotiledonar à extremidade do primeiro par de folhas, e da raiz primária, distância do nó cotiledonar à extremidade da raiz primária, das plântulas normais identificadas no final do teste de germinação; o somatório dos comprimentos das duas estruturas forneceu o comprimento da plântula. Os resultados foram obtidos por meio do quociente entre o somatório das medidas das plântulas normais e o número de plântulas avaliadas (Nakagawa, 1994).

Massa de matéria seca de plântulas - As plântulas normais, separadas do restante das estruturas das sementes, foram acondicionadas em saco de papel e colocadas em estufa a $70^{\circ} \mathrm{C} \pm 2^{\circ} \mathrm{C}$ por 48 horas, previamente às pesagens. A massa de matéria seca, em g/plântula foi obtida por meio do quociente entre o somatório de massas de plântulas normais e o número de plântulas avaliadas.

O delineamento experimental adotado foi o inteiramente casualizado, com sete tratamentos (teores de água) e quatro repetições. Os dados em porcentagem foram transformados em arco seno da raiz quadrada de $\mathrm{x}+0,5$ e os demais em raiz quadrada de $x+0,5 / 100$. As médias foram comparadas pelo teste de Tukey, a $5 \%$ de probabilidade.

\section{RESULTADOS E DISCUSSÃO}

Na Figura 1 estão representados os valores de teores de

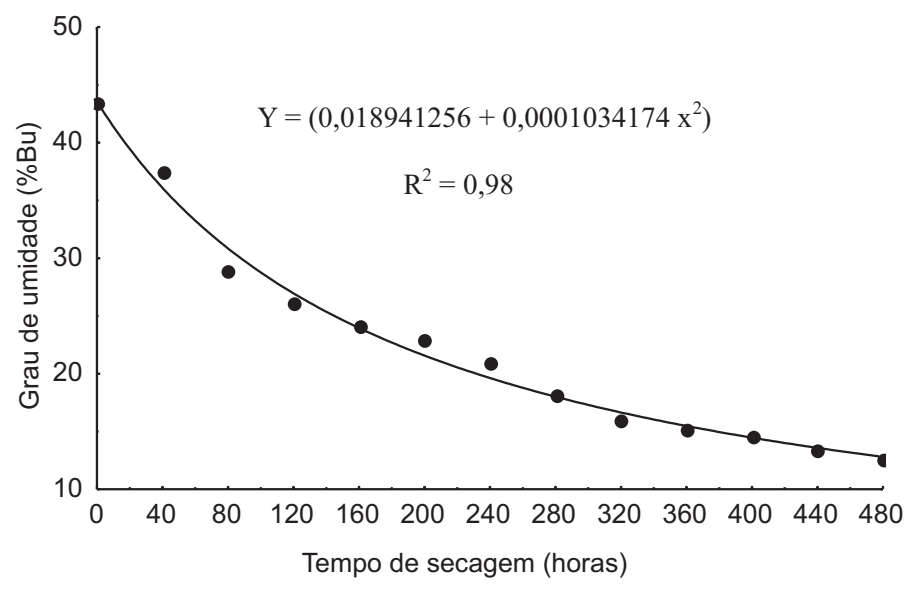

FIGURA 1. Evolução do grau de umidade de sementes de $\boldsymbol{E}$. oleracea, durante o tempo de secagem a $30^{\circ} \mathrm{C} \pm 2^{\circ} \mathrm{C}$. Piracicaba, 2004.

água das sementes durante o processo de secagem. Esses valores foram próximos aos planejados, indicando a eficiência do método utilizado no monitoramento do processo de secagem para a obtenção dos tratamentos.

A secagem adotada pode ser considerada lenta, sendo necessárias 480 horas para a redução do teor de água das sementes de 43,4\% para 11,9\% (Figura 1). De acordo com Pammenter et al. (1998), a secagem lenta não é adequada para sementes recalcitrantes e pode provocar danos à estrutura das membranas. Porém, independente do tempo de desidratação, as sementes recalcitrantes não sobrevivem quando dessecadas abaixo de certos limites, em geral mais elevados que os observados para a sobrevivência de espécies ortodoxas (Marcos Filho, 2005).

Por meio dos dados relativos às determinações fisiológicas (Tabela 1) foi observada ausência de efeitos imediatos da desidratação até $37,4 \%$ de teor de água; a partir de 30,3\%, houve redução na qualidade fisiológica das mesmas. $\mathrm{O}$ avanço no processo de secagem afetou o desempenho das sementes de açaí de forma que, ao atingirem 26,0\% de água, houve redução acentuada da germinação inviabilizando sua utilização em semeaduras comerciais. Essa perda tornou-se máxima quando o teor de água atingido foi de $15,1 \%$, o que foi verificado pela perda total da germinação. Pesquisadores como Oliveira et al. (2000) e Nascimento e Silva (2004) identificaram também esse teor de água como o limitante para a germinação de sementes de açaí.

A desidratação crescente afetou o vigor, com o aumento do tempo médio de germinação, redução da velocidade de emergência de plântulas, do comprimento e da massa de matéria seca de plântulas (Tabela 1). Figueirêdo et al. (1993) 
também constataram reduções da velocidade de emergência, da matéria seca de plântulas e da germinação de sementes de E. oleracea, desidratadas até $28 \%$ de água, por 5 horas a $35^{\circ} \mathrm{C}$.

Para os testes de vigor a tendência dos resultados foi similar à verificada para a germinação, evidenciando os efeitos negativos da dessecação sobre a qualidade fisiológica das sementes, confirmando, dessa maneira, o comportamento recalcitrante das sementes de açaí relatado por Martins et al. (1999a), Araújo et al. (1994) e por Carvalho et al. (1998).
Essas sementes são consideradas intolerantes à dessecação e perdem a viabilidade quando o teor de água é reduzido abaixo de valores críticos. Para Marcos Filho (2005) os mecanismos de proteção que deveriam atuar em nível celular são ineficientes ou inexistentes nas sementes recalcitrantes.

Na Figura 2, são apresentados às curvas de germinação das sementes com diferentes teores de água. Observou-se que o dessecamento além de reduzir a porcentagem de germinação, causou retardamento no início da germinação, especialmente quando o teor de água foi reduzido para valor

TABELA 1. Germinação (G), tempo médio de germinação (TM), velocidade de emergência (IVE), comprimento (CP) e massa de matéria seca (MS) de plântulas, determinados em sementes de E. oleracea . Piracicaba, 2004.

\begin{tabular}{cccccc}
\hline Tratamento (grau de umidade \%) & $\mathrm{G}^{(\mathbf{1})}(\%)$ & TM (dia) & IVE & CP (cm) & MS (g/plântula) \\
\hline 43,4 & $92 \mathrm{a}$ & $47 \mathrm{a}$ & $0,020 \mathrm{ab}$ & $15,7 \mathrm{a}$ & $0,440 \mathrm{a}$ \\
37,4 & $88 \mathrm{a}$ & $46 \mathrm{a}$ & $0,023 \mathrm{a}$ & $15,2 \mathrm{a}$ & $0,399 \mathrm{a}$ \\
30,3 & $80 \mathrm{~b}$ & $52 \mathrm{~b}$ & $0,018 \mathrm{~b}$ & $15,3 \mathrm{a}$ & $0,272 \mathrm{~b}$ \\
26,1 & $42 \mathrm{c}$ & $63 \mathrm{c}$ & $0,016 \mathrm{~b}$ & $10,5 \mathrm{~b}$ & $0,144 \mathrm{c}$ \\
21,0 & $07 \mathrm{~d}$ & $67 \mathrm{c}$ & $0,016 \mathrm{~b}$ & $9,0 \mathrm{~b}$ & $0,021 \mathrm{~d}$ \\
15,1 & $00 \mathrm{e}$ & $00 \mathrm{~d}$ & $0,000 \mathrm{c}$ & $0,0 \mathrm{c}$ & $0,000 \mathrm{e}$ \\
11,9 & $00 \mathrm{e}$ & $00 \mathrm{~d}$ & $0,000 \mathrm{c}$ & $0,0 \mathrm{c}$ & $0,000 \mathrm{e}$ \\
\hline C.V. $(\%)$ & 2,45 & 2,83 & 1,51 & 6,83 & 1,68 \\
\hline
\end{tabular}

${ }^{(1)}$ Médias seguidas da mesma letra, nas colunas, não diferem entre si pelo teste de Tukey a 5\% de probabilidade.

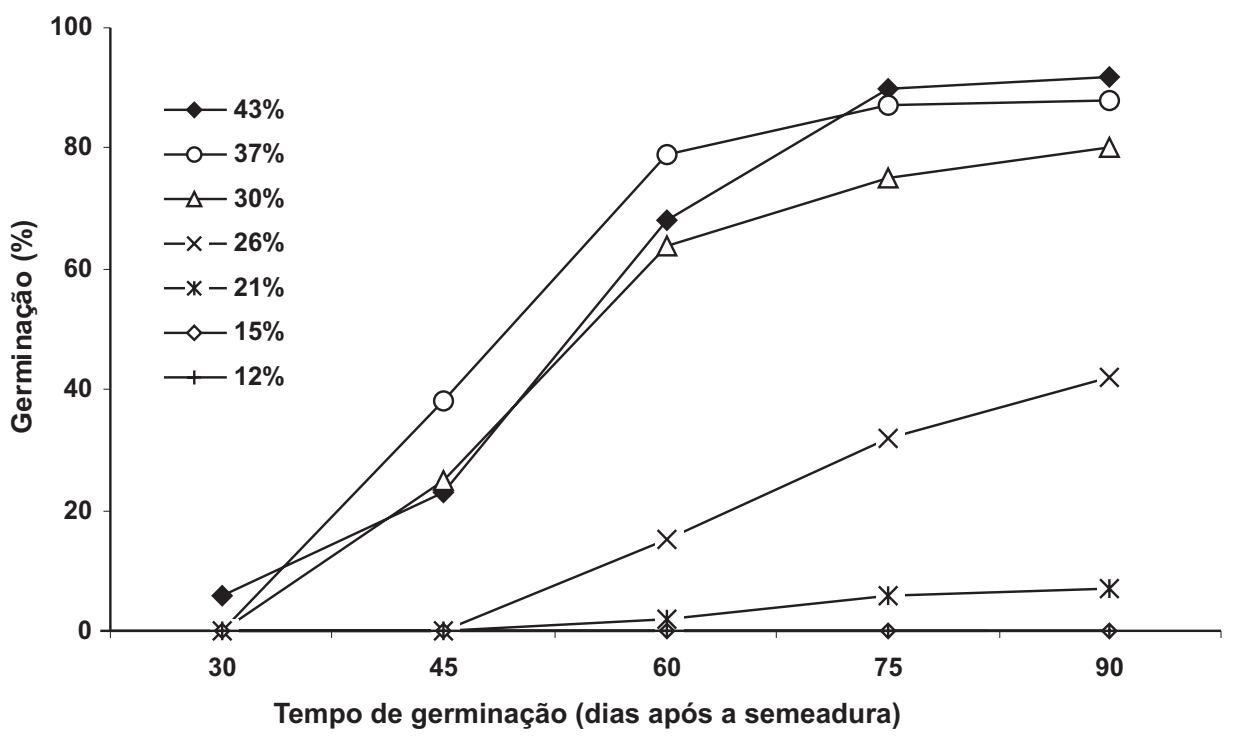

FIGURA 2. Germinação de sementes de E. oleracea, em função do tempo e do grau de umidade de sementes. Piracicaba, 2004. 
igual ou inferior a 30,3\%. Em quase todos os casos, as curvas de germinação exibiram padrão sigmóide, exceção feita para as curvas referentes as sementes com teores de água abaixo de $26,1 \%$, que apresentou tendência linear, o que pode ser explicado pela baixa porcetagem de sementes germinadas. Carvalho e Müller (1998) verificaram também o aumento do tempo requerido para a germinação das sementes de pupunha na medida em que ocorreu a dessecação.

O ambiente em que as sementes se desenvolvem é importante para determinar o padrão de tolerância à dessecação. A umidade relativa do ar baixa no momento da dispersão da semente pela planta-mãe favorece a síntese de mecanismos de reparos os quais irão conferir às sementes, maior ou menor tolerância à dessecação. Por outro lado, as sementes de espécies tropicais, que apresentam o seu desenvolvimento em ambiente com alta umidade relativa, praticamente não perdem água durante a maturação, portanto, não há formação desses mecanismos de proteção e as sementes podem sofrer injurias quando submetidas à secagem.

A comprovação da importância do ambiente sobre o comportamento das sementes pode ser verificado pelos resultados obtidos para as sementes de açaizeiro, os quais assemelham-se aos observados para Euterpe espiritosantensis (Martins et al., 1999b), Euterpe edulis (Martins et al., 2000) e em Bactris gasipaes (Bovi et al., 2004), palmáceas pertencentes a hábitat semelhante ao de Euterpe oleracea Mart.

\section{CONCLUSÕES}

A secagem até 37,4\% de teor de água não produz efeitos imediatos prejudiciais sobre o desempenho fisiológico das sementes de açaí.

Abaixo de 30,3\% de teor de água, há redução progressiva na germinação e vigor das sementes, e ao atingirem 15,1\% de teor de água, as sementes não germinam.

\section{AGRADECIMENTOS}

In memorian ao professor Walter Rodrigues da Silva, pela orientação na elaboração e condução do trabalho.

\section{REFERÊNCIAS}

ANDRADE, C.S.; PEREIRA, T.S. Comportamento de armazenamento de sementes de palmiteiro (Euterpe edulis Mart.). Pesquisa Agropecuária Brasileira, Brasília, v.32, n.10, p.987-991,
1997.

ARAÚJO, E.F; SILVA, R.F.; ARAÚJO, R.F. Avaliação da qualidade de sementes de açaí armazenadas em diferentes embalagens e ambientes. Revista Brasileira de Sementes, Brasília, v.16, n.1, p.76-79, 1994.

BOVI, M.L.A.; MARTINS, C.C.; SPIERING, S.H. Desidratação de quatro lotes de pupunheira: efeitos sobre a germinação e o vigor. Horticultura Brasileira, Brasília, v.22, n.1, p.109-112, 2004.

BRASIL. Ministério da Agricultura e da Reforma Agrária. Regras para análise de sementes. Brasília: SNDA/DNDV/CLAV, 1992. 365p.

CARVALHO, J.E.U.; NASCIMENTO, W.M.O.; MÜLLER, C.H. Características físicas e de germinação de sementes de espécies frutíferas nativas da Amazônia. Belém: EMBRAPA/CPATU, 1998. 18p. (Boletim de Pesquisa, 203).

CARVALHO, J.E.U.; MÜLLER, C.H. Níveis de tolerância e letal de umidade em sementes de pupunheira, Bactris gasipaes. Revista Brasileira de Fruticultura, v.20, n.3, p.283-289, 1998.

CROMARTY, A.S.; ELLIS, R.H.; ROBERTS, E.H. Design of seed storage facilities for genetic conservation. Rome: IPGRI, 1985. 100p.

FARRANT, J.M.; PAMMENTER, N.W.; BERJAK, P. Recalcitrance - a current assessment. Seed Science and Technology, Zürich, v.16, n.1, p.155-166, 1988.

FIGUEIRÊDO, F.J.C.; CARVALHO, J.E.U.; MÜLLER, C.H. Efeito imediato da secagem sobre a emergência e vigor de sementes de açaizeiro. Informativo ABRATES, Brasília, v.3, n.3, p.47,1993.

MAGUIRE, J.D. Speed of germination: aid in selection and evaluation for seedling emergence and vigour. Crop Science, Madison, v.2, n.2, p.176-177, 1962.

MARCOS FILHO, J. Fisiologia de sementes de plantas cultivadas. Piracicaba: FEALQ, 2005. 495p.

MARTINS, C.C.; NAKAGAWA, J.; BOVI, M.L.A.; STANGUERLIM, H. Teores crítico e letal de água para sementes de açaizeiro (Euterpe oleracea Mart.). Revista Brasileira de Sementes, Campinas, v.21, n.1, p.125-132, 1999a.

MARTINS, C.C.; NAKAGAWA, J.; BOVI, M.L.A. Tolerância à dessecação de sementes de palmito-vermelho (Euterpe espiritosantensis Fernandes). Revista Brasileira de Botânica, São Paulo, v.22, n.3, p.125-132, 1999 b.

MARTINS, C.C.; NAKAGAWA, J.; BOVI, M.L.A. Desiccation tolerance of four seedlots from Euterpe edulis Mart. Seed Science and Technology, Zürich, v.28, n,1, p.101-113, 2000.

NAKAGAWA, J. Testes de vigor baseados na avaliação das plântulas. In: VIEIRA, R.D; CARVALHO, N.M. (Ed.). Testes de vigor em sementes. Jaboticabal: FUNEP, 1994. p.49-85.

NASCIMENTO, W.M.O.; SILVA, W.R. Comportamento fisiológico de sementes de açaí (Euterpe oleracea Mart.) submetidas à desidratação. In: CONGRESSO BRASILEIRO DE FRUTICULTURA, 18., 2004, Florianópolis. Anais... Florianópolis: SBF/IPAGRI, 2004. CD ROM.

OLIVEIRA, M S. P.; CARVALHO, J.E.U.; NASCIMENTO, W.M.O. Açaí (Euterpe oleracea Mart.). Jaboticabal: FUNEP, 2000. 52p. (Série frutas nativas, 7). 
PAMMENTER, N.W.; GREGGAINS, V.; KIOKO, J.I.; WESLEYSMITH, J.; BERJAK, P. Effects of differential drying rates retention of Ekebergia capensis. Seed Science Research, Cambridge, v.8, n.4, p. 463-471, 1998.

SILVA, J.B.C.; NAKAGAWA, J. Estudo de fórmulas para o cálculo da velocidade de germinação. Informativo ABRATES, Londrina, v.5, n.1, p.62-73, 1995.
STATSOFT. Statistical for windows. General conventions and statistics, statsoft, Tulsa. OK. Inc. 1998.

VILLACHICA, H.; CARVALHO, J.E.U.; MÜLLER, C.H.; DIAZ S.C.; ALMANZA, M. Frutales y hortalizas promissorios de la Amazonia. Lima: Tratado de Cooperacion Amazonica. Secretaria Pro-tempore, 1996. 367p. (TCT-SPT, 44). 